American Journal of Infectious Diseases 4(2): 104-108, 2008

ISSN 1553-6203

(C) 2008 Science Publications

\title{
The Use of a Combination Vaccine in International Travelers Visiting Countries with High Endemic Rates of Hepatitis A and/or Hepatitis B
}

\author{
${ }^{1}$ Bradley A. Connor, ${ }^{2}$ Susan Anderson and ${ }^{3}$ Robert Steffen \\ ${ }^{1}$ Division of Gastroenterology and Hepatology, The Weill Medical College of Cornell University \\ and The New York Center for Travel and Tropical Medicine, New York \\ ${ }^{2}$ Division of Infectious Disease and Geographic Medicine, \\ Stanford University School of Medicine, Fremont, California \\ ${ }^{3}$ University of Zurich Travel Health Center, \\ WHO Collaborating Center for Travelers' Health, Zurich CH-8006, Switzerland
}

\begin{abstract}
Hepatitis A and B represent a significant threat to international travelers. Both diseases are preventable through vaccination, though fewer than half of at-risk visitors in endemic regions are protected. Current vaccination recommendations should be revised to ensure adequate immunity for all international travelers against hepatitis $\mathrm{A}$ and $\mathrm{B}$, as both diseases pose comparable danger. Since exposure to the viruses cannot be predicted, vaccination should be offered to all individuals visiting destinations with intermediate or high endemicities of hepatitis A and/or B, regardless of length of stay and standard of accommodation. Risk groups and endemicity of hepatitis A and B overlap, therefore, a combination vaccine against both forms is beneficial.
\end{abstract}

Key words: Twinrix, travel medicine, hepatitis vaccination

\section{INTRODUCTION}

The hepatitis A and B viruses (HAV and HBV, respectively) are considerable threats to the health of international travelers. Both viruses have a substantial global prevalence and the likelihood of infection is particularly high in developing regions such as Latin America, the Caribbean, Africa, Asia and parts of Eastern Europe (Fig. 1) ${ }^{[1]}$. With an estimated infection rate of 3.0-11.0 per 100,000 visitors per month of stay, hepatitis $\mathrm{A}$ is regarded as one of the most common vaccine-preventable diseases among travelers visiting developing countries ${ }^{[2]}$. Symptomatic infection with $\mathrm{HBV}$ in unvaccinated travelers is seen at a slightly higher frequency, occurring in approximately 20-60 per 100,000 persons per journey ${ }^{[3]}$. Nevertheless, rates for both forms of hepatitis likely underestimate the actual risk for infection, as they do not take into account asymptomatic cases or individuals diagnosed and treated while abroad.

In 2005, 4,488 clinical cases of acute hepatitis A were reported in the United States (US) ${ }^{[4]}, 16 \%$ of which were reportedly due to exposure during international travel ${ }^{[5]}$. Despite an improvement from previous years, the estimated total number of cases of

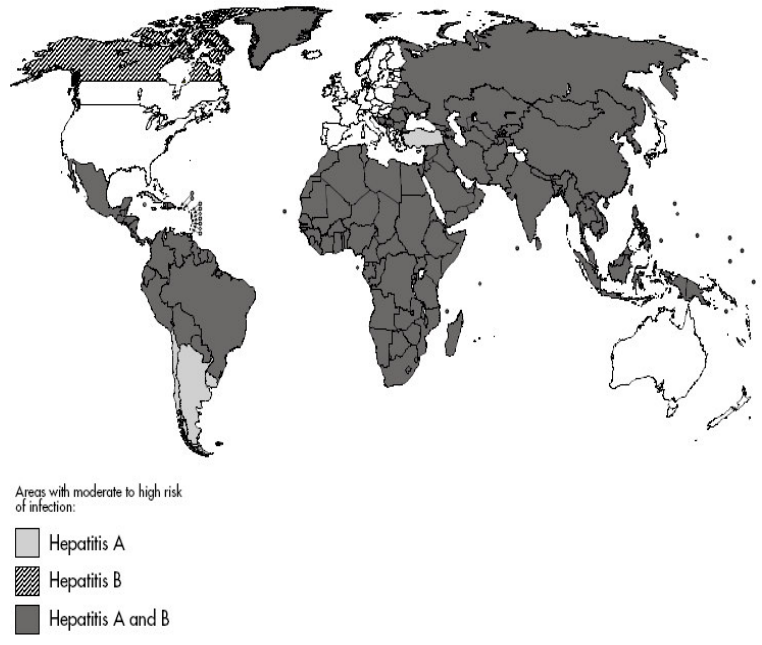

Fig. 1: Areas with moderate to high risk of infection

HAV (including asymptomatic patients) reached as many as $19,000^{[4]}$. Acute HBV infections are somewhat less common, with 5,494 reported clinical cases and an estimated 15,000 symptomatic and asymptomatic cases in $2005^{[4]}$. However, the true impact of HBV was reflected in the additional $1.25 \mathrm{~m}$ people in the US who

Corresponding Author: Bradley A. Connor, Division of Gastroenterology and Hepatology,

Weill Medical College of Cornell University, New York Center for Travel and Tropical Medicine, New York, New York 10021 
developed chronic disease as a result of infection and the 3,000-5,000 deaths due to chronic liver disease ${ }^{[4]}$.

\section{IMPACT}

In terms of reduced productivity and impact on healthcare resources, hepatitis generates a significant economic burden. For example, in 1997, 63,363 recorded symptomatic HAV infections in the US were associated with 829,000 lost working days, over 8,000 hospitalizations and an annual overall cost of more than $\$ 480 \mathrm{~m}^{[6]}$. Although no data are currently available on the specific costs of HBV, acute infections, or longterm treatment for chronic infections, it may be assumed that each contributes a significant amount to the overall burden.

Although self-limiting, the infections may incapacitate the individual for an average of 4-10 weeks ${ }^{[7]}$. Life threatening, fulminant disease may also occur from either form of infection. The case fatality rate for hepatitis A increases with age ${ }^{[8]}: 0.3 \%$ for people aged 15-39 years, greater than $2 \%$ for people aged over 40 years and $4 \%$ for people aged over 60 years ${ }^{[1,8]}$. In comparison, $1 \%$ of hepatitis B cases result in death ${ }^{[1]}$.

Although chronic disease is not a feature of HAV infection, approximately $10 \%$ of those infected with HBV do develop chronic disease, in which serious long-term complications such as hepatocellular carcinoma, chronic hepatitis and cirrhosis ensue. These complications are responsible for much of the morbidity and mortality associated with hepatitis $\mathrm{B}^{[9]}$. Furthermore, individuals with chronic infection pose a serious public health risk, as they may be asymptomatic and remain infectious ${ }^{[9]}$.

\section{RISK OF TRANSMISSION}

Hepatitis A is a picornavirus that replicates in the liver and is excreted in stool ${ }^{[10]}$. Transmission is enabled via the fecal-oral route and is exacerbated by poor hygiene and overcrowding ${ }^{[10]}$. Travelers are often at an increased risk of acquiring $\mathrm{HAV}$ as a result of eating and drinking in locations considered high-risk HAV areas ${ }^{[11]}$. Typical culprits for contamination include water, shellfish and uncooked or unpeeled fruits and vegetables $^{[11]}$. In high-endemic regions, infection and immunity typically occur in childhood, whereas in developed countries, improved sanitation and hygiene have naturally lowered the immunity to HAV and most adults are susceptible to infection unless vaccinated ${ }^{[11]}$.

Hepatitis B is a hepadnavirus that is transmitted through blood, serous fluids, saliva and $\operatorname{semen}^{[12]}$.
Infection is spread by sexual contact and the risk of transmission is heightened by sexual promiscuity ${ }^{[12]}$. Percutaneous transmission is also possible, as the virus can be spread in extremely small quantities of blood. Activities that lead to percutaneous infection include needle sharing during drug abuse, cosmetic or grooming procedures (such as piercing, tattooing, or cosmetic surgery), exposure to contaminated blood products during transfusion and dental or medical intervention (injections, intravenous drug administration, suturing, surgery or acupuncture) with non-sterile needles and equipment ${ }^{[11,13,14]}$.

\section{IMMUNOPROPHYLAXIS}

Internationally, monovalent vaccines against $\mathrm{HAV}$ and HBV have been available since 1991 and 1981, respectively. These vaccines were introduced in the US in 1995 and 1986, respectively. Inactivated HAV vaccines, administered according to the recommended two dose schedule (single primary immunization followed by a second dose 6-18 months later), result in seroconversion in $94-100 \%$ of vaccine recipients within one month of the primary dose, with rates of $100 \%$ seroconversion observed after administration of the second dose $\mathrm{s}^{[8,15]}$. Recombinant HBV vaccines are also highly effective; a three dose schedule $(0,1$ and 6 months) typically safeguards $>90 \%$ of adults and $>95 \%$ of infants, children and adolescents ${ }^{[9]}$.

A combination $\mathrm{HAV}$ and $\mathrm{HBV}$ vaccine (Twinrix $^{\mathrm{TM}}$, GlaxoSmithKline Biologicals; Rixensart, Belgium) has been available since 1996 and is as well tolerated and immunogenic as monovalent vaccines ${ }^{[16-20]}$. Risk destinations for HAV and HBV infection overlap considerably (Fig. 1) ${ }^{[1]}$, so travelers, in particular, should be protected against both viruses. A major proportion of the population in the US and in other industrialized nations will travel to developing countries $^{[21]}$, and most will need double protection during their lifetime. Simultaneous vaccination against HAV and HBV allows several advantages, including fewer injections for the patient, as well as simplified vaccination schedules and lower administration costs for healthcare providers ${ }^{[19]}$. An accelerated schedule of injections should be initiated for patients close to the time of travel.

\section{COMPARING CURRENT VACCINATION RECOMMENDATIONS}

Although childhood vaccination programs against HBV have been in use since $1995^{[22]}$ and recommendations for childhood vaccination against 
Am. J. Infect. Dis., 4(2): 104-108, 2008

Table 1: Hepatitis A and B Vaccination recommendations for travelers

\begin{tabular}{|c|c|c|}
\hline Recommending body & Hepatitis A & Hepatitis B \\
\hline $\mathrm{WHO}^{\mathrm{a}[1]}$ & $\begin{array}{l}\text { Travelers to countries with moderate-to-high risk of } \\
\text { infection. Individuals at high risk for acquiring HAV, } \\
\text { irrespective of their travel destination. }\end{array}$ & $\begin{array}{l}\text { All travelers to countries with moderate-to-high risk of } \\
\text { HBV infection. All individuals at high risk of acquiring } \\
\text { HBV, irrespective of their travel destination. }\end{array}$ \\
\hline $\mathrm{CDC}^{\mathrm{b}[23]}$ & $\begin{array}{l}\text { Individuals traveling to countries with high or intermediate } \\
\text { endemicity of HAV. Screening is alternatively recommended } \\
\text { for persons who may have had prior HAV infection and } \\
\text { where screening costs are lower than vaccination costs. }\end{array}$ & $\begin{array}{l}\text { Travelers to countries with high or intermediate prevalence } \\
\text { of chronic HBV infection (HbsAg prevalence in } \geq 2 \% \text { of } \\
\text { the population) who will have close contact with the local } \\
\text { population, or who are considered at-risk groups. }\end{array}$ \\
\hline CATMAT $^{\mathrm{c}[24]}$ & $\begin{array}{l}\text { Non-immune travelers to developing countries, especially } \\
\text { if traveling to rural areas, HAV endemic areas, or areas } \\
\text { where hygiene is likely to be poor. }\end{array}$ & $\begin{array}{l}\text { Travelers residing for }>6 \text { months in countries where HBV } \\
\text { is endemic. Travelers likely to have close contact with } \\
\text { residents of endemic areas, irrespective of length of stay. }\end{array}$ \\
\hline $\operatorname{Travax}^{\mathrm{d}}$ & $\begin{array}{l}\text { All travelers to countries with moderate-to-high HAV } \\
\text { endemicity. }\end{array}$ & $\begin{array}{l}\text { Travelers to areas with a high risk of HBV for prolonged } \\
\text { periods of time, those undertaking frequent shorter stays } \\
\text { in the same or other high-risk areas and all travelers } \\
\text { planning any high-risk behavior. Vaccination may also be } \\
\text { appropriate for short-stay travelers who wish to be } \\
\text { protected against HBV, in the event of requiring medical } \\
\text { care from local facilities in HBV endemic areas. }\end{array}$ \\
\hline IDSA $^{\mathrm{e}[25]}$ & $\begin{array}{l}\text { All travelers to areas of the world where hygiene } \\
\text { may be poor. }\end{array}$ & $\begin{array}{l}\text { Travelers planning long-term trips or repeated trips. } \\
\text { Consideration should be given to the immunization of all } \\
\text { adults regardless of travel plans. }\end{array}$ \\
\hline
\end{tabular}

a: WHO, World Health Organization; ${ }^{\mathrm{b}}$ : CDC, Centers for Disease Control and Prevention; ${ }^{\mathrm{c}}$ : CATMAT, Committee to Advise on Tropical Medicine and Travel (on behalf of the Public Health Agency of Canada); ${ }^{\mathrm{d}}$ : Travax are leading sources of information for the US CDC, the WHO and the US Department of State, among many others; ${ }^{\mathrm{e}}$. IDSA, Infectious Diseases Society of America

HAV have recently been introduced ${ }^{[10]}$, the majority of adults in the US are not yet immunized against either form of hepatitis ${ }^{[19]}$. The current strategy for adults is to vaccinate only high-risk individuals ${ }^{[21]}$. The likelihood of international travelers contracting hepatitis A and/or $\mathrm{B}$ is determined by the region visited, the duration of the visit and the planned activities during the stay. The focus on HBV varies considerably between recommendations (Table 1$)^{[1,23-25]}$.

\section{COMPARING RISK EXPOSURE TO VACCINATION RATES}

A large proportion of adults in the US may be at high risk for contracting viral hepatitis. In a survey of 1,034 US adults, $49 \%$ met the Advisory Committee on Immunization Practices (ACIP) criteria for vaccination against HAV, with journeys to endemic regions being the most common risk factor among respondents ${ }^{[21]}$. Similarly, in a survey among 618 US international travelers, $45 \%$ were exposed to at least one HBV risk factor during their most recent trip to an HBV prevalent region and $8 \%$ were classified as high-risk travellers ${ }^{[26]}$. Exposure to HBV may also occur from short-duration trips. During a trip from Canada to an HBV-rife destination that lasted an average of less than six weeks, $15 \%$ of 410 visitors participated in hazardous activities $^{[27]}$. Despite high risks for infection, studies have reported low vaccination rates among visitors to areas of high endemicity. For example, in the aforementioned survey of 618 US travelers, only $19 \%$ were vaccinated and only $30 \%$ of those considered at high risk of infection completed the recommended vaccination series ${ }^{[26]}$. In a second survey involving more than 9,000 travelers visiting moderate or high prevalence areas for $\mathrm{HBV}$, the overall vaccination rate was only $16.9 \%{ }^{[13]}$. Even when stratified by risk, the protection rate for those in the highest risk category (6.6-11.2\% of the overall population) was still poor, leaving three of every four people involved in unsafe behavior open to infection. Additionally, interviews carried out among 201 adults traveling from the US to regions with high levels of HAV found a similar lack of planned protection, with only $14 \%$ and $13 \%$ vaccinated against hepatitis $\mathrm{A}$ and $\mathrm{B}$, respectively ${ }^{[28]}$.

\section{REASSESSING THE RECOMMENDATIONS: REBALANCING VACCINATION PRIORITY}

Both HAV and HBV pose significant threats to international travelers, with respective incidences of 311 in $100,000^{[2]}$ and $20-60$ in $100,000^{[3]}$ per journey and equal consideration should be given to the prevention of both forms of hepatitis through vaccination. Although current guidelines acknowledge HAV as a major health concern, the importance of HBV is underestimated and vaccination for all travelers to $\mathrm{HBV}$ endemic zones should be actively encouraged. In addition, individuals planning an extended stay in an HBV endemic area are recognized by guidelines as candidates for vaccination, while those staying for only a short period of time may be overlooked, but they are also at risk of contracting an HBV infection ${ }^{[27]}$. 
Cumulative lifetime exposure must also be considered. While vaccination is recommended for people planning unsafe behavior (such as tattooing or unsafe sex) while visiting a hepatitis B endemic area, activities leading to HBV may not always be planned. Up to $3 \%$ of people visiting developing countries experience an injury during their visit ${ }^{[13,27]}$, which may necessitate medical intervention and lead to HBV exposure from a contaminated instrument or blood product. Also, of the estimated $64 \%$ of individuals who become ill while visiting developing countries, $8 \%$ seek medical attention, $17 \%$ of whom receive potentially unsafe injections ${ }^{[29]}$. The threat posed by use of nonsterile equipment in developing countries is considerable, as $0.9 \%$ of all US travelers to these destinations receive an injection during their stay ${ }^{[29]}$, and one in three injections are administered unsafely ${ }^{[14]}$. Emergency dental care is another example by which a person may unexpectedly heighten their risk of HBV infection.

\section{CONCLUSIONS}

All children in the US are now immunized against hepatitis A and B through a universal childhood mass vaccination program, which, in turn, will reduce the number of future infections in adults. Meanwhile, further consideration should be given to recommendations regarding catch-up vaccination of non-immune adults, regardless of whether or not their destinations include hepatitis endemic areas.

In vaccination programs, hepatitis $\mathrm{A}$ has historically been considered of greater importance than hepatitis B. The balance should be readdressed and recommendations should acknowledge hepatitis $\mathrm{B}$ as an equal threat. The revision of vaccination recommendations is particularly important in light of increasing travel of US residents to developing countries. Although current guidelines advise hepatitis $B$ vaccination for high-risk groups visiting endemic areas, exposure to hepatitis B cannot always be predicted. Unintentional injuries pose a real threat to both long- and short-term travelers.

Therefore, in addition to vaccination against hepatitis $\mathrm{A}$, vaccination against hepatitis $\mathrm{B}$ should be offered to everyone visiting areas where $\mathrm{HBV}$ is widespread, regardless of their length of stay. Protecting individuals before travel will safeguard the community to which they return.

\section{ACKNOWLEDGEMENT}

Editorial support provided by AlphaBioCom.

\section{REFERENCES}

1. World Health Organization, International Travel and Health. http://www.who.int/ith/en.

2. Mutsch, M., V.M. Spicher, C. Gut and R. Steffen, 2006. Hepatitis A virus infections in travelers, 1988-2004. Clin. Infect. Dis., 42: 490-497.

3. Steffen, R., 1990. Risks of hepatitis B for travellers. Vaccine, 8 (Suppl): S31-S32.

4. Centers for Disease Control and Prevention. Disease burden from hepatitis in the United States. http://www.cdc.gov/ncidod/diseases/hepatitis/resou rce/disease_burden.htm.

5. Centers for Disease Control and Prevention, Hepatitis surveillance report No. 61. http://www.cdc.gov/ncidod/diseases/hepatitis/resou rce/PDFs/hep_surveillance_61.pdf.

6. Berge, J.J., D. Drennan and R.J. Jacobs et al., 2000. The cost of hepatitis A infections in American adolescents and adults in 1997. Hepatology, 31: 469-473.

7. Gutersohn, T., R. Steffan and P. Van Damme et al., 1996. Hepatitis A infection in aircrews: Risk of infection and cost-benefit analysis of hepatitis A vaccination. Aviat. Space. Environ. Med., 67(2): 153-6.

8. World Health Organization, Hepatitis A. http://www.who.int/csr/disease/hepatitis/whocdscsr e>dc2007/en/.

9. Centers for Disease Control and Prevention, 2005. Hepatitis B. In: Epidemiology and Prevention of Vaccine-Preventable Disease. 8th Ed. CDC, Atlanta, pp: 207-231.

10. Centers for Disease Control and Prevention, 2006. Prevention of hepatitis A through active or passive immunization. MMWR. 55 (RR-7): 1-23.

11. Khuroo, M., 2003. Viral hepatitis in international travellers: Risks and prevention. Int. J. Antimicrobial Agents, 21: 143-152.

12. Centers for Disease Control and Prevention, 2005. A comprehensive immunization strategy to eliminate transmission of hepatitis B virus infection in the United States: Part I. MMWR. 54 (RR-16): 1-24.

13. Zuckerman, J.N. and R. Steffen, 2000. Risks of hepatitis $\mathrm{B}$ in travelers as compared to immunization status. J. Travel. Med., 7: 170-174.

14. Hutin, Y.J.F., A.M. Hauri and G.L. Armstrong, 2003. Use of injections in healthcare settings worldwide, 2000: Literature review and regional estimates. Br. Med. J., 327: 1075-1076. 
15. Centers for Disease Control and Prevention, 2005. Hepatitis A. In: Epidemiology and Prevention of Vaccine-Preventable Disease. 8th Ed. CDC, Atlanta, pp: 193-206.

16. Bruguera, M., J.M. Bayas and A. Vilella et al., 1996. Immunogenicity and reactogenicity of a combined hepatitis $\mathrm{A}$ and $\mathrm{B}$ vaccine in young adults. Vaccine, 14: 1407-1411.

17. Kallinowski, B., A. Knoll and E. Lindner, 2001. Can monovalent hepatitis $\mathrm{A}$ and $\mathrm{B}$ vaccines be replaced by a combined $A / B$ vaccine during the primary immunization course? Vaccine, 19: 16-22.

18. Thoelen, S., P. Van Damme and A. LeentvaarKuypers et al., 1999. The first combined vaccine against hepatitis A and B: An overview. Vaccine, 17: 1657-1662.

19. Joines, R.W., M. Blatter and B. Abraham et al., 2001. A prospective, randomized, comparative US trial of a combination hepatitis $\mathrm{A}$ and $\mathrm{B}$ vaccine (Twinrix ${ }^{\mathrm{TM}}$ ) with corresponding monovalent vaccines (Havrix $®$ and Engerix-B®) in adults. Vaccine, 19: 4710-4719.

20. Tsai, I.J., M.H. Chang and H.L. Chen et al., 2001. Immunogenicity and reactogenicity of the combined hepatitis A and B vaccine in young adults. Vaccine, 19: 437-441.

21. Jacobs, R., A.S. Meyerhoff and T. Zink, 2005. Hepatitis A immunization strategies: universal targeted approaches. Clin. Pediatrics, 44: 705-709.
22. Centers for Disease Control and Prevention, 1995. Recommended childhood immunization scheduleUnited States, January 1995. MMWR. 43: 959943.

23. Centers for Disease Control and Prevention. Health Information for International Travel. 2005-2006. http://www.cdc.gov/travel/yb/ (Accessed October 2006).

24. The Committee to Advise on Tropical Medicine and Travel (CATMAT), 2001. Statement on hepatitis A vaccines for travelers. Canada Communicable Disease Report, 27: 3-12.

25. Hill, D.R., D.C. Ericsson and R.D. Pearson et al., 2006. The practice of travel medicine: Guidelines by the infectious diseases society of America. Clin. Infect. Dis., 43: 1499-1539.

26. Connor, B.A., R.J. Jacobs and A.S. Meyerhoff, 2006. Hepatitis B risks and immunization coverage among American travelers. J. Travel Med., 13: 273-280.

27. Correia, J.D., R.T. Shafer and V. Patel et al., 2001. Blood and body fluid exposure as a health risk for international travelers. J. Travel Med., 8: 263-266.

28. Hamer, D.H. and B.A. Connor, 2004. Travel health knowledge, attitudes and practices among United States travelers. J. Travel Med., 11: 23-26.

29. Hill, D.R., 2000. Health problems in a large cohort of Americans traveling to developing countries. J. Travel Med., 7: 259-266. 